\title{
Integrating ACAD with GIS for Civil Engineering Applications
}

\author{
Asma Thamir Ibraheem, Haidar Alaa Hassan, Mustefa Husam Abd Al-Husain
}

Civil Engineering Department, College of Engineering, Nahrain University, Baghdad, Iraq.

Email: drasmathamir@yahoo.com

Received November $9^{\text {th }}, 2011$; revised December $11^{\text {th }}, 2011$; accepted January $9^{\text {th }}, 2012$

\begin{abstract}
GIS is a computerized database management system that provides geographic access (capture, storage, retrieval, analysis and display) to spatial data. Civil Engineering projects involve the management, analysis and integration of large amounts of geographic information to ensure success. This can include a wide range of information such as detailed design drawings originating from CAD solutions, detailed mapping, air photography, geological investigations, population information, traffic flows and environmental models. Although there are some similarities between CAD and GIS there are many differences. The most fundamental difference is that GIS mode is the world as it exists, whereas CAD models artifacts yet to be produced. As a result the data manipulated by a GIS is an order of magnitude larger and more complex than CAD systems have to deal with, and the nature of the data, its sources and its uses are quite different. In this paper, the selected area was Nahrain University. Many data were saved on the site map as a transparence layers built by using AutoCAD (2006). Then a digital library was built for the selected area and many data were saved on the site map as a themes built by using ArcView software.
\end{abstract}

Keywords: CAD; Civil Engineering; Computer; GIS; Spatial Data

\section{Introduction}

Geographic information system (GIS) integrates hardware, software, and data for capturing, managing, analyzing, and displaying all forms of geographically referenced information.

GIS allows users to view, understand, question, interpret, and visualize data in many ways that reveal relationships, patterns, and trends in the form of maps, globes, reports, and charts. Also GIS helps the user to answer questions and solve problems by looking at data in a way that is quickly understood and easily shared. GIS technology can be integrated into any enterprise information system framework [1].

A GIS is most often associated with a map. A map, however, is only one way that can work with geographic data in a GIS, and only one type of product generated by a GIS. A GIS can provide a great deal more problemsolving capabilities than using a simple mapping program or adding data to an online mapping tool (creating a “mash-up”). A GIS can be viewed in three ways [2]:

1) The Database View: A GIS is a unique kind of database of the world-a geographic database (geo-database). It is an "Information System for Geography." Fundamentally, a GIS is based on a structured database that describes the world in geographic terms.
2) The Map View: A GIS is a set of intelligent maps and other views that show features and feature relationships on the earth's surface. Maps of the underlying geographic information can be constructed and used as "windows into the database” to support queries, analysis, and editing of the information.

3) The Model View: A GIS is a set of information transformation tools that derive new geographic datasets from existing datasets. These geoprocessing functions take information from existing datasets, apply analytic functions, and write results into new derived datasets.

\section{Historical Background}

Several developments in the field of computer sciences during the last few decades helped the realization of the GIS concept. The most important one of course, is the invention of the digital computer during the 1940s.

In 1963, the introduction of a software and hardware system gave birth to computer-aided design (CAD), which had much influence on the development of automatic map drafting systems [3].

Next, the influence of database management systems appeared during the 1970s. The rapid developments during recent years, in areas such as distributed processing systems, continue to shape GISs of the next generation. 
Since the number of systems increase readily as a result of the development of the computer techniques and equipment, like satellite scanning systems and the increase of images in digital forms.

Nowadays, numbers of systems have been developed in land use fields, map production, general services and in the private establishments. Most of these systems depend on data taken from maps and can processed to get desired local information in geographical or grid coordinates according to the selected projections; like Arc/Info, Kern Maps 200, computer aided data compilation for the analytical plotters, and INFOCAM for geographical information systems [3].

Upper management should not mandate GIS technology if local support does not exist. Regional coordination can facilitate and assist local managers in evaluating GIS potentials.

Implementation of a major centralized GIS computing facility is not feasible for every region, but some centralized GIS coordination should be implemented either for the region as a whole or within individual programs. Centralized coordination can facilitate documentation and inventory of existing data bases, assist in coordination with other agencies in digital data transfer and interagency data sharing, and provide other specialized GIS services. The centralized coordination will increase enterprise benefits across the Service and will serve as a focal point for GIS activities within the Service.

Decentralized systems can easily handle incremental increases in users and applications as demand for GIS capabilities increases. Decentralized systems have the advantage of being more acceptable in a complex institutional environment where different organizational entities can better justify operating with a distributed processor. Given the geographically scattered locations of Service offices as well as the concept of eco-region management, "Nodes" and "Satellites" should be developed within each eco-region (or other manageable division such as a state).

\section{GIS and CAD}

The ability of GIS to search databases and perform geographic queries has revolutionized many areas of science and business. It can be invaluable during a decisionmaking process. The information can be presented succinctly and clearly in the form of a map and accompanying report, allowing decision makers to focus on the real issues rather than trying to understand the data. Because GIS products can be produced quickly multiple scenarios can be evaluated efficiently and effectively. For this reason, in today's world, the ability to use GIS is increasingly important [2].

The difference between CAD and GIS systems is becoming blurred with the internal attributes and database linkages enhancing CAD's capabilities. At their core,
CAD and GIS are complementary technologies that have evolved largely independently but in parallel over the past 30 years. ESRI's longtime best-of-breed approach provides value to engineers by building better linkages between CAD and GIS systems [4].

As it is clearly in Figure 1, the main differences between CAD and GIS are:

1) GIS is a database program, and CAD is a graphics program.

2) With CAD, it's the lines that are important, i.e. the drawing is the information.

3) With GIS, the lines are just a representation of the data behind it.

4) GIS data model, while similar to CAD approach in that it uses coordinates, is fundamentally different in its simplicity and approach.

Although there are some similarities between CAD and GIS there are many differences. The most fundamental difference is that GIS models the world as it exists, whereas CAD models artifacts yet to be produced. As a result the data manipulated by a GIS is an order of magnitude larger and more complex than CAD systems have to deal with, and the nature of the data, its sources and its uses are quite different.

\section{GIS Technology}

GIS technology is increasingly being considered for implementation in many infrastructure planning and management systems, due to its superior spatial data handling capabilities. Textual databases are combined with digitized maps to enable the visual display of various data on a map. GIS technology plays an increasing role in the development of new pavement management applications for all concerned transportation agencies. The sophisticated database in a GIS has the ability to associate and manipulate diverse sets of spatially referenced data that have been geo-coded to a common referencing system. GIS can expand the decision making on repair strategies and project scheduling by incorporating such diverse data as accident histories, and vehicle volumes. A GIS can perform geographic queries in a straightforward, intuitive fashion rather than being limited to textual queries. Thus GIS are now used by [5]:

- Business;

- Tourism;

- Communications;

- Defence and Intelligence;

- Educators;

- Engineering;

- Cellular Network;

- Environmental Management;

- Government;

- Health and Human Services;

- Natural Resources; 
GIS

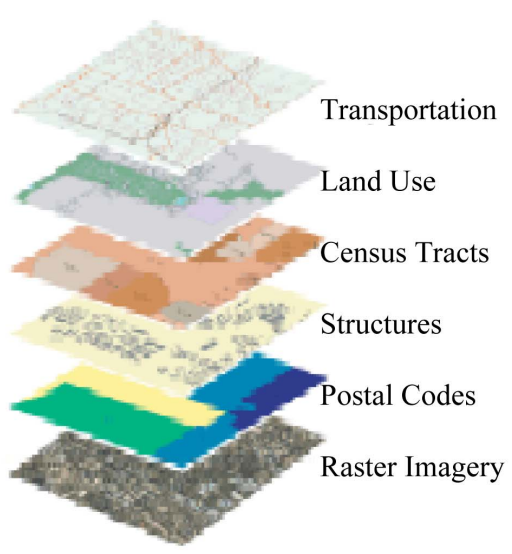

vs.

CAD
- Transportation;

- Utilities.

Also GIS are used for the following common reasons [6]:

- GIS is computer based, and has all the advantages (and disadvantages) of a computer tool;

- GIS is established in many workplaces and has proven not to be a passing fad;

- GIS can be an accurate, efficient, effective and scientific tool;

- GIS can be used to improve organizational integration;

- GIS helps to make better decisions;

- GIS makes maps.

\section{Benefits of GIS}

The common benefits of GIS are as follows [7]:

- Ensures current, accurate data by Public Safety GIS experts;

- Provides standardized process for timely data delivery for your GIS environment;

- Affords varying levels of service available from one company (advanced to basic);

- Provides data in standardized ESRI formats;

- Increases control of data maintenance;

- Offers seamless service: we are divided into teams for cross-functional project overlap;

- Offers largest public safety GIS staff in the industry;

- Provides cost efficiencies of hiring a contractor.

\section{GIS Applications in Civil Engineering}

With increasingly complex projects, the interaction of often international multidisciplinary functions requires the introduction of effective and efficient data management and sharing solutions. GIS provides the civil engineer with tools for creating, managing, analyzing and visualizing all types of geographic information. GIS is now being used by Civil Engineers in every application domain and throughout every aspect of the enterprise, be it on the desktop, in the field, or in collaboration with others.

Some of these applications are, as it is concluded in

Figure 2:

- Centralized Data Management;

- Asset Management;

- Transportation;

- Water Resources;

- Environmental Monitoring.

\section{Integrating ACAD with GIS}

CAD tools combined with GIS data, is a powerful tool to the land-use suitability analysis problem. Essential components of this combination are the decision maker's preferences, tradeoff evaluations, and assessments of the importance of criteria for any transportation project.

Nowadays geographic information systems (GIS) and CAD are widely used in different applications. Experience shows that the combination of GIS and CAD is an efficient tool for selection best route for distributed linear objects such as railways, roads and pipelines. And selection best location for distributed polygonal objects such as rail station, landfill, park and etc.

Also geographic information systems (GISs) are appropriate for managing and accessing digital library data, and particularly collections of spatial data such as maps or images of the earth. But, they are also appropriate for any collection that can be geographically referenced. Furthermore, advanced GIS tools can link library collections; that is, GIS and coordinate information can be used as a general purpose indexing system to library collections. This would make it possible to access virtually all objects collected by a library that are geographically referenced. 

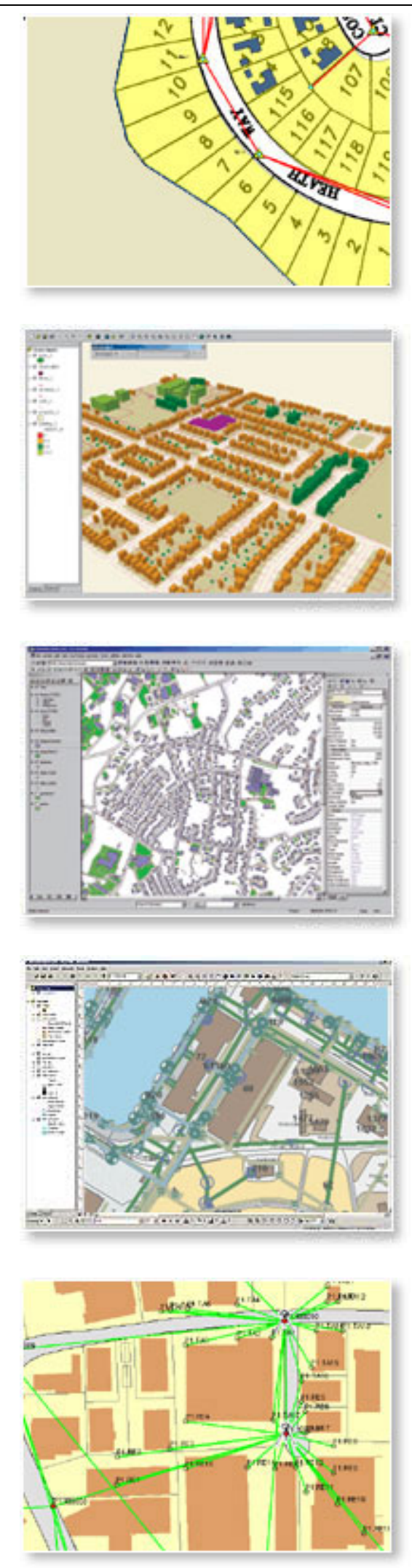

\section{Centralised Data Management}

GIS portal technology provides the ideal environment managing and sharing information collected during engineering projects.

\section{AssetManagement}

GIS is a powerful framework for monitoring the use and distribution of assets, tracking location, condition and age of capital assets and infrastructure, and measuring asset lifecycles, maintenance costs and depreciation.

\section{Transportation}

Transport projects utilise GIS to bring together data to enhance decision making.

\section{Water Resources}

GIS provides water resource planners and engineers with an intelligent database so job planning, equipment inventory and flow analysis become part of an automated procedure integrated into one system.

\section{Environmental Monitoring}

Environmental monitoring projects use GIS to collect, integrate, manage and visualise geographic information.

Figure 2. GIS applications in civil engineering [7]. 


\section{Developing GIS Maps by Using ACAD Software}

AutoCAD allows the use of nearly 300 tools. Some operators prefer using the word "commands", although command as an alternative to tool is not in common use today. The abbreviations for tools which can be abbreviated are included in brackets after the tool name. Tool names can be entered in upper or lower case [8]. The main tool is how to make the required layers. Figure 3 shows the Layer Properties Manager.

By this way, nineteen layers were built in this paper for the case study as it is clear in Figure 4.

\section{Developing GIS Maps by Using ArcView Software}

ArcView is a Geographical Information System, GIS, which runs on a wide variety of different computer systems, (often called "platforms"). ArcView behaves in exactly the same way on each of these platforms. There are some tools in ArcView, which cannot operate in certain computing environments; these have been introduced as "Extensions" from ArcView Release 3.3 and will only be met in the more advanced, optional, units of this tutorial.

In ArcView terminology, a View comprises one or more Themes. Each theme is simply a distinct set of information such as roads or rivers or county boundaries etc., rather like the different layers that can be used to build up a map. In addition, each Theme has its own legend, which is a list of the symbology used. Note how the name of the theme with its symbol appears in the View Legend area, together with a little selection box just to the left of the name.

Figure 5 shows the ACAD map showing some of the districts of al Nahrain University, which are developed in the previous section. This map is used as the base of building a new GIS to make an initial data base for the

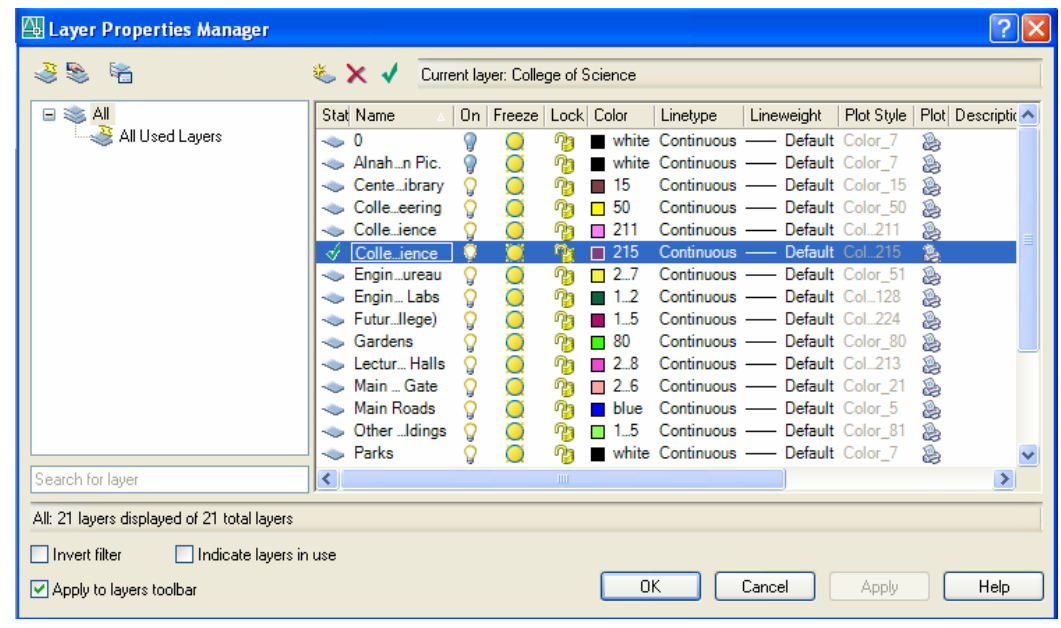

Figure 3. The layer properties manager.

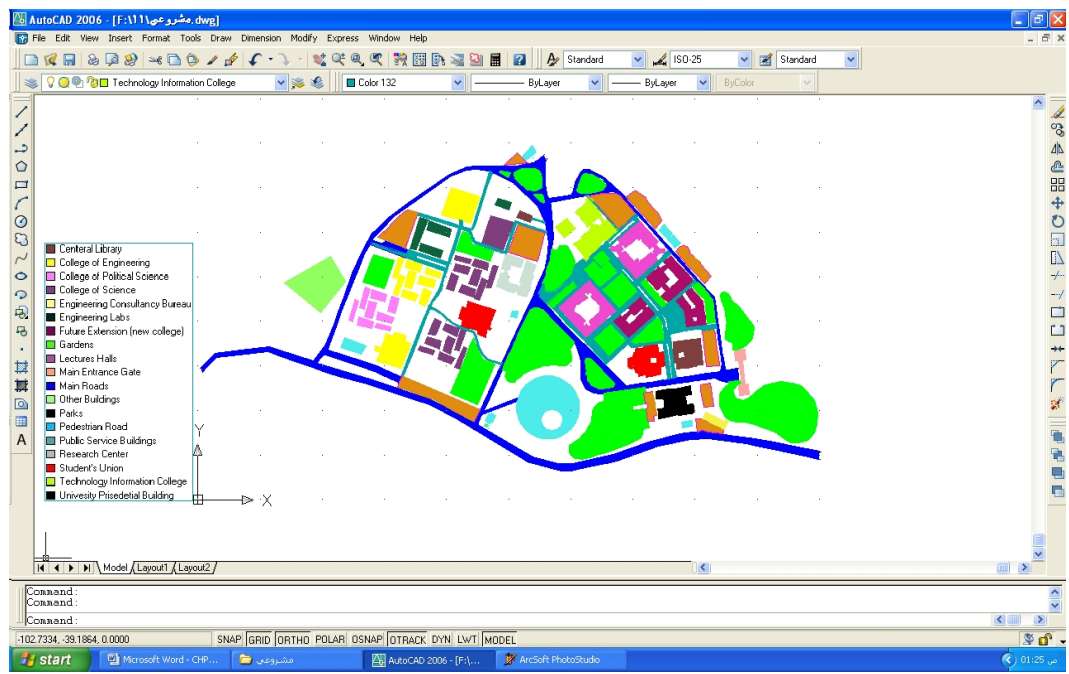

Figure 4. The layers of nahrain university site map. 


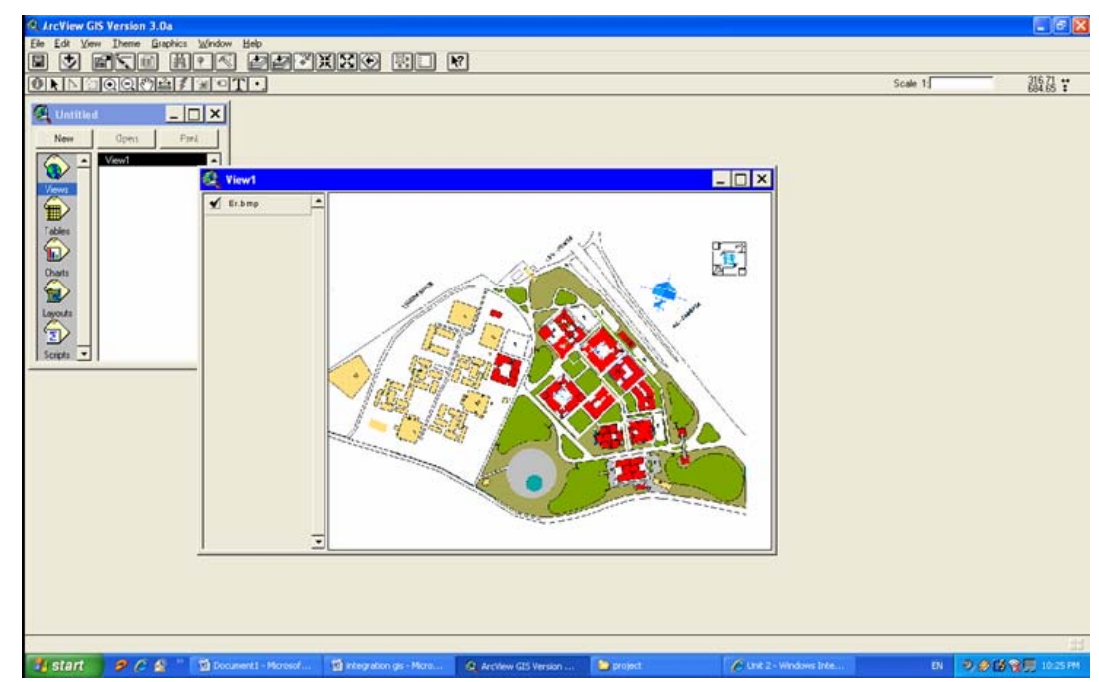

Figure 5. Map selection.

university site.

In order to add a new theme to the view, the following steps should be followed:

1) Click the Add Theme icon. Alternatively, you can click View on the Menu Bar and then Add Theme from the drop-down menu displayed.

2) You should now see the Add Theme dialogue box as shown in Figure 6, which will be listed in the left hand part of the window, although the files and directories listed will, of course, be those, available from the institution.

After saving the new theme we can now to draw a new theme like the circular as shown in Figure 7.

By this way we make the following thems:

1) Land use theme: in this theme will notice all university buildings content the building that not construct yet as shown in Figure 8.

2) Garden theme: this theme contents all the garden of university as shown in Figure 9.

3) Park theme: this theme contents all the parks of university as shown in Figure $\mathbf{1 0 .}$

4) Major roads: this theme notices the major roads of the university as shown in Figure 11.

By select all the themes the land use, gardens, parks and major roads the map will be as shown below in Figure 12.

Then we can input importance information on any map like name, area and type of any building or road and that can be done by using a TABLE command in this program where a table will appear and we can input all information in it. For Al Nahrain University we input the name of buildings and as it is clear in Figure 13.

\section{Conclusions}

On the basis of the project findings, the following conclusions are appropriate:
1) GIS has an important application for example in civil engineering projects like involve the management, analysis and integration of large amounts of geographic information to ensure success. This can include a wide range of information such as detailed design drawings originating from CAD solutions, detailed mapping, air photography, geological investigations, population information, traffic flows and environmental models.

2) Although there are some similarities between CAD and GIS there are many differences. The most fundamental difference is that GIS models the world as it exists, whereas CAD models artifacts yet to be produced. As a result the data manipulated by a GIS is an order of magnitude larger and more complex than CAD systems have to deal with, and the nature of the data, its sources and its uses are quite different.

3) The difference between CAD and GIS systems is becoming blurred with the internal attributes and database linkages enhancing CAD's capabilities.

4) GIS is a database program, and CAD is a graphics program. With CAD, it's the lines that are important, i.e. the drawing is the information. With GIS, the lines are just a representation of the data behind it.

5) The integration of GIS concepts into civil engineering still faces many challenges. Besides financial and technical problems, the lack of understanding the importance of GIS education by civil engineering educators may be one of the most critical issues that deserve special attention.

6) GIS resources on the Internet and GIS on-line activities will benefit education. GIS on-line education should be included in the study domain of spatial information system. This will benefit not only for civil engineers but also other professionals.

7) In order to make the linking between CAD and GIS easier and more benefit, the present work shall be re- 


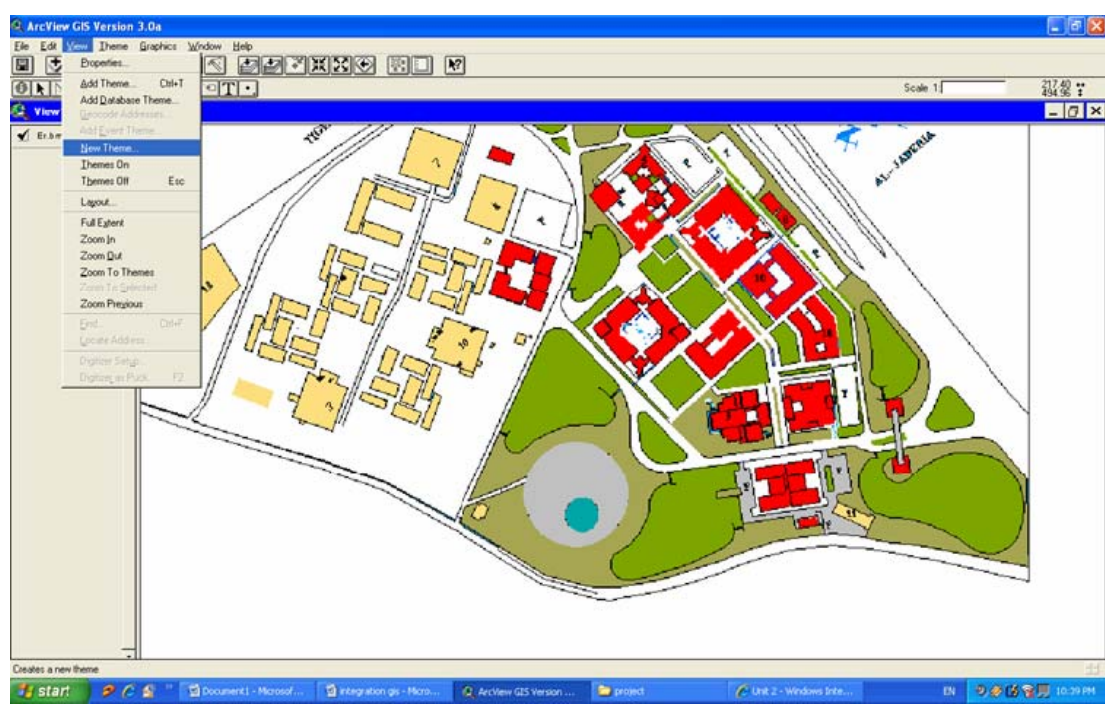

Figure 6. Making theme 1.

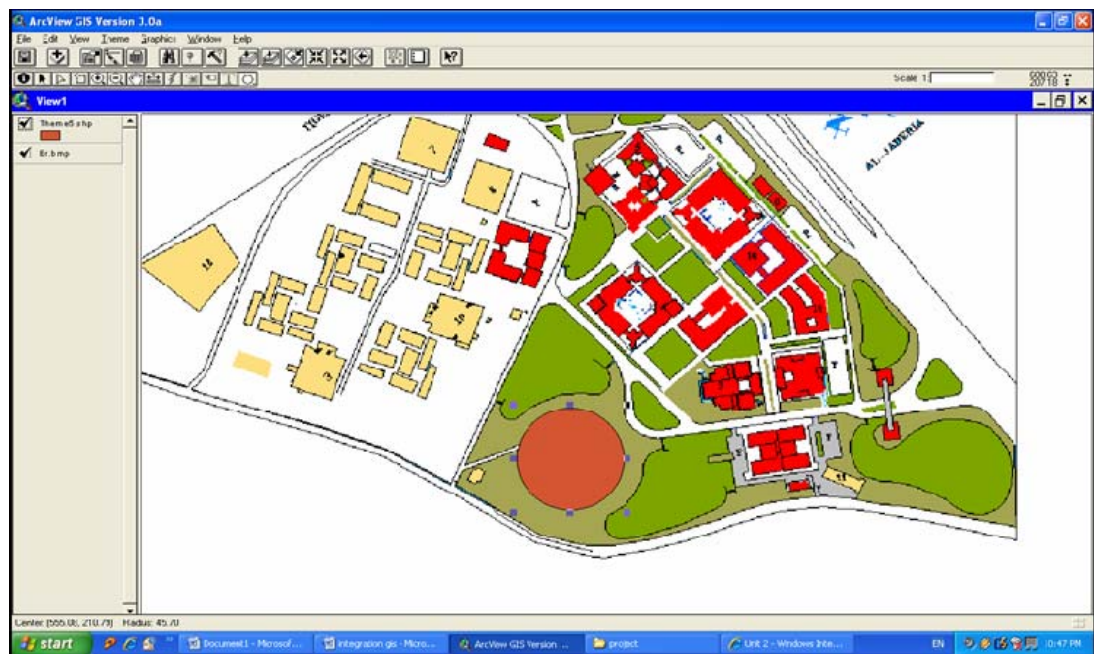

Figure 7. Adding a new theme.

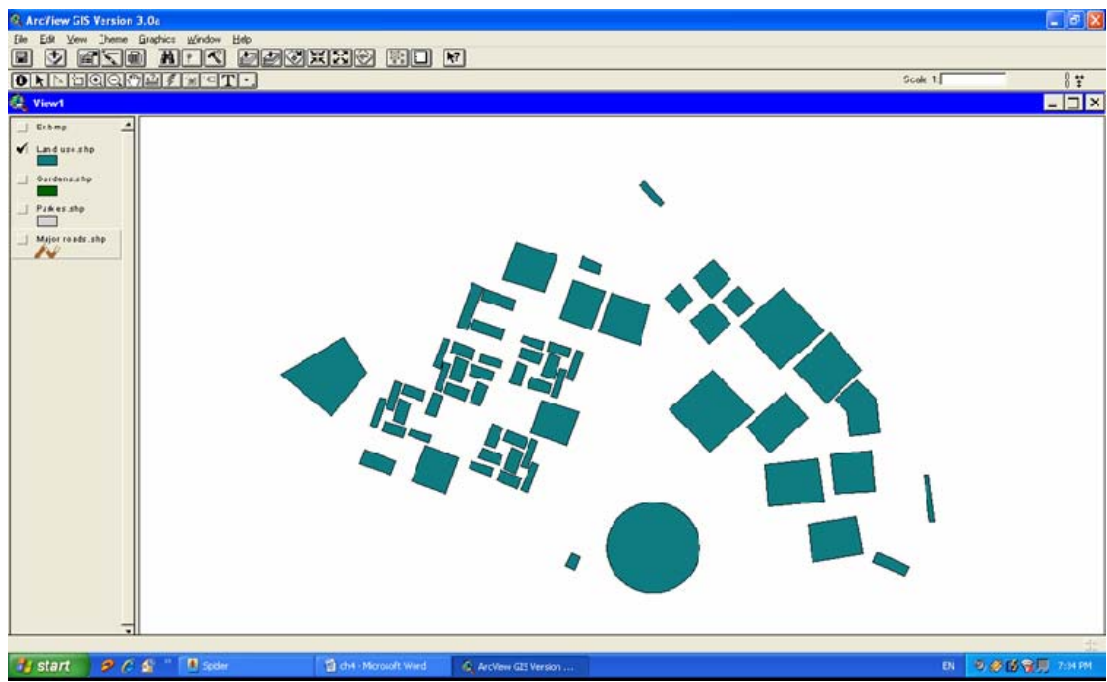

Figure 8. Land use theme. 


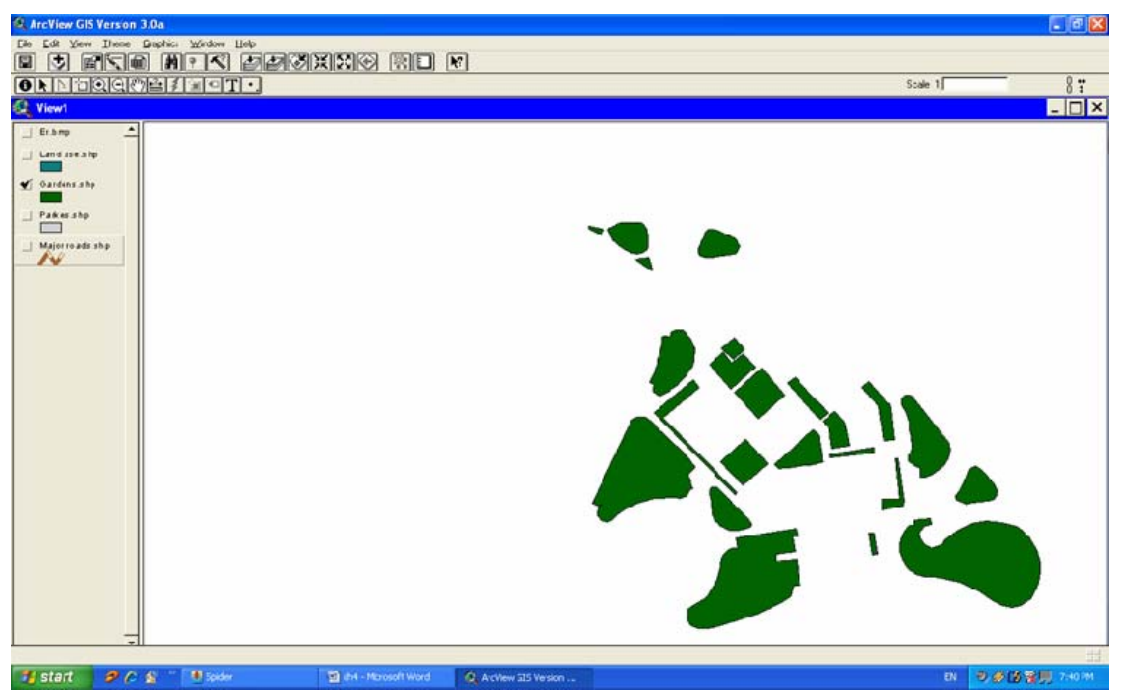

Figure 9. Garden theme.

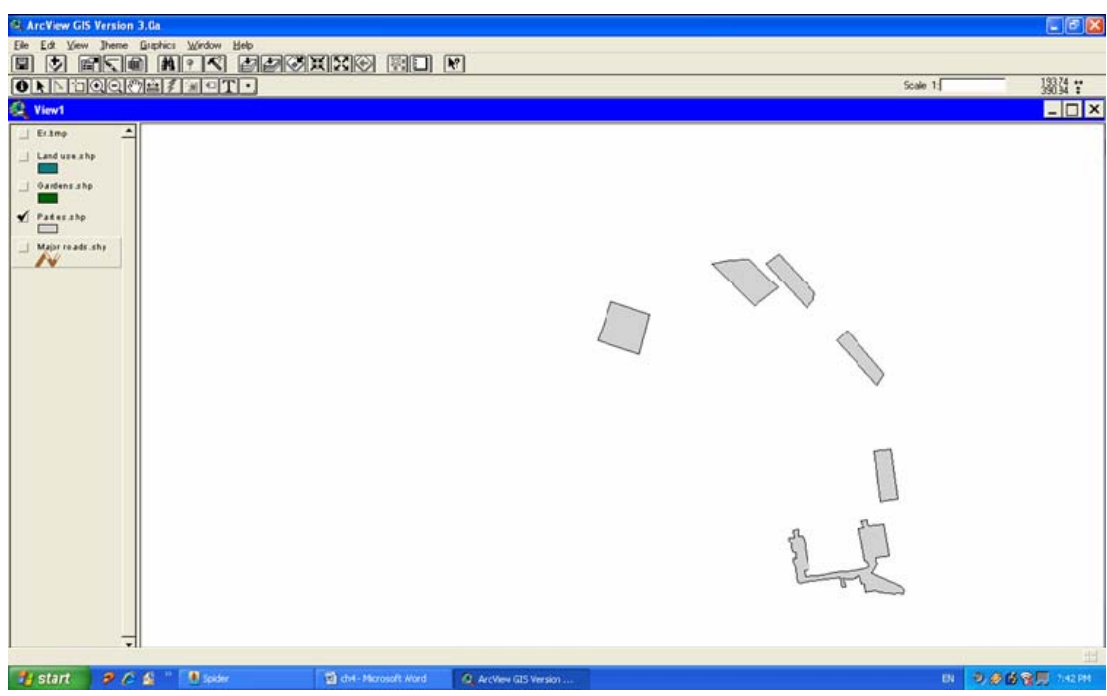

Figure 10. Park theme.

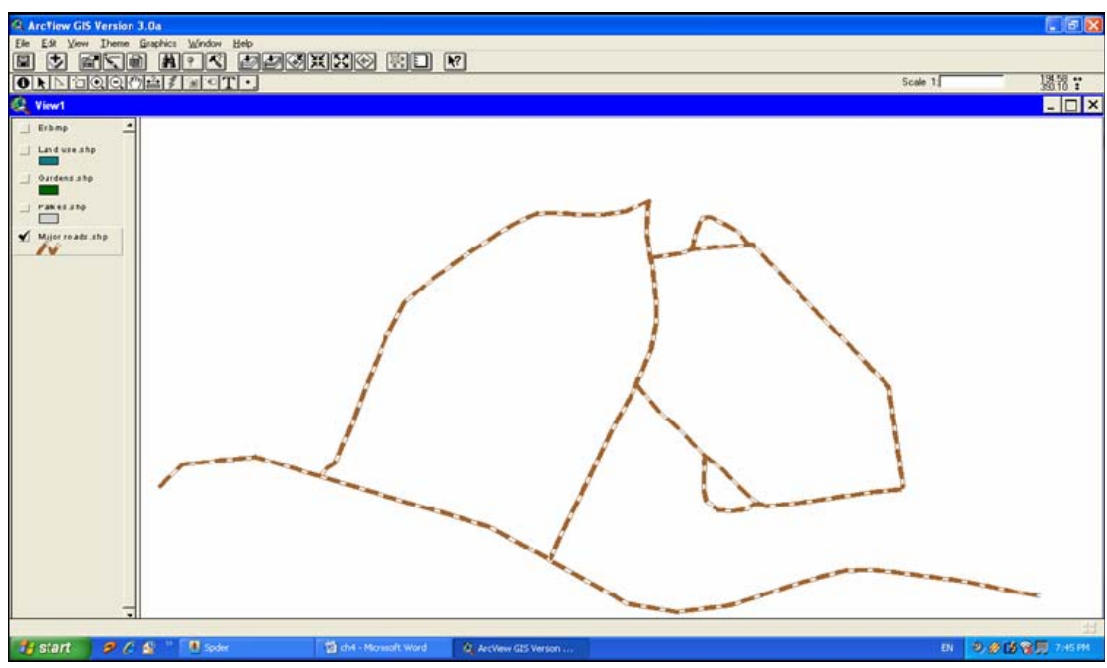

Figure 11. Major road theme. 


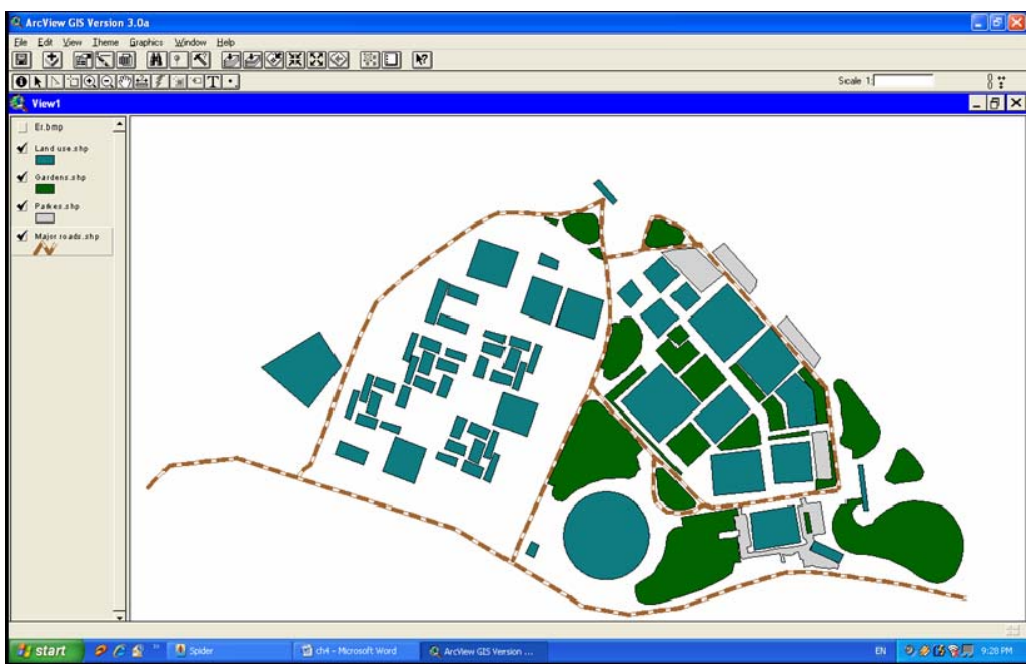

Figure 12. Whole themes.

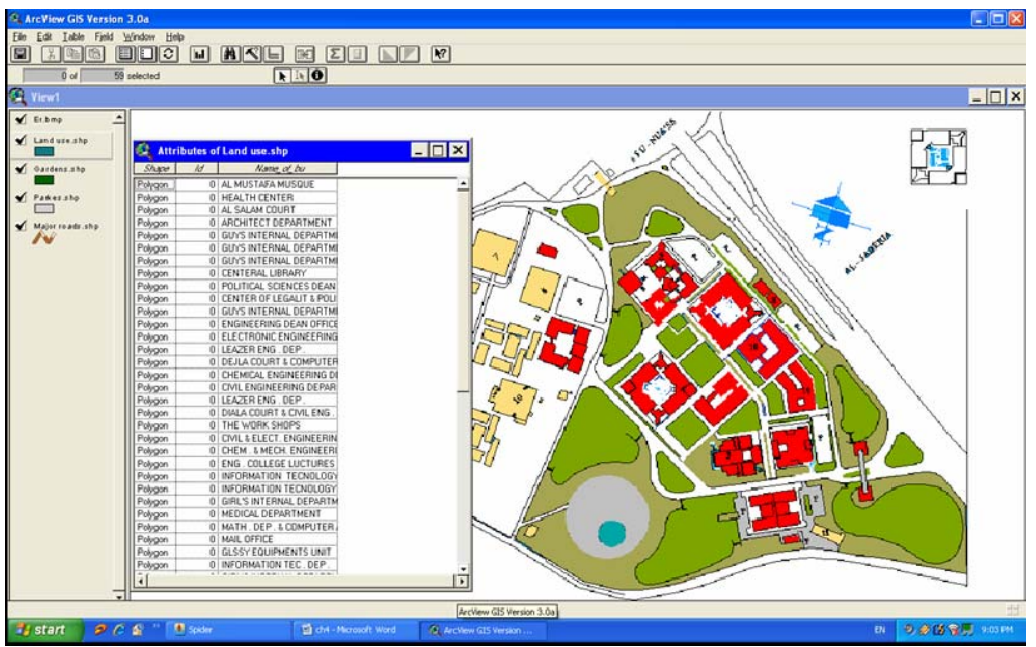

Figure 13. Input data.

peated by using ArcGIS software.

\section{REFERENCES}

[1] J. Dangennond and A. Schutzberg, "Basic of Geographic Information System," Journal of Computing in Civil Engineering, Vol. 12, No. 7, 1998, pp. 121-122.

[2] www.GIS.htm, “Geographic Information System,” Copyright 2010, Holstead \& Redmond Limited, 2010. http://www.gis.com/whatisgis/viewofgis/index.html/ http://www.gis.com/whatisgis/whyusegis.html http://www.gis.com/whatisgis/whatcanyoudowithgis.html http://www.gis.com/implementing_gis/index.html

[3] A. Ibraheem, "The Utilization of Local Resources to Develop a GIS in Surveying and Route Design,” M.Sc. Thesis, College of Engineering, University of Baghdad, Baghdad, 1997.

http://www.scirp.org/journal/paperinformation.aspx?paperid $=17099$
[4] H. Tim, "CAD versus GIS Which Is Better for Automated Mapping,” University of Missouri, Columbia, 2001.

[5] T. Bernhardsen, “Geogrphic Information Systems,” Wiley Inc., New York, 1999.

[6] A. Th Ibraheem and D. A. Falih, "Applying Geographic Information System (GIS) for Maintenance Strategy Selection,” Engineering Journal (ENG), Scientific Research Publication, Vol. 4, No. 1, 2012, pp. 44-54.

http://www.scirp.org/journal/paperinformation.aspx?pape rid=17099

[7] A. Th Ibraheem, "The Application of Geographical Information System in Civil Engineering,” Integration Teaching and Research with Community Service, College of Engineering, University of Sharjah, Sharjah, Book No. 87, 2008, pp. 436-455.

[8] Y. Alf, "An Introduction to AutoCAD 2006 2D and 3D Design,” British Library Cataloguing-in-Publication Data, 2006. 